\title{
A imagem de pensamento como forma
}

\author{
The Thought-Image as Form \\ http://dx.doi.org/10.11606/1982-8837203221
}

Fabio Akcelrud Durão ${ }^{1}$

\begin{abstract}
This text strives to characterize the thought-image (Denkbild) as a genre that combines philosophy and literature, concept and image. The main argument therein is that due to its formal peculiarities, the thought-image is endowed with both a strong intersubjetive thrust and the capacity to wrest the non-identical from everyday experiences. From this combination a kind of writing emerges that is intrinsically practical, and which deserves to be recuperated in the present.
\end{abstract}

Keywords: Thought-Image; Critical Theory; Frankfurt School.

Resumo: Este texto busca caracterizar a imagem de pensamento (Denkbild) como um gênero particular de composição que mistura filosofia e literatura, conceito e imagem. $\mathrm{O}$ argumento central é o de que, devido às suas peculiaridades formais, a imagem de pensamento possui tanto um forte teor intersubjetivo, quanto a capacidade como de fazer surgir o não-idêntico em experiências cotidianas. Desse combinação surge um tipo de escrita prática, que merece ser recuperada no presente.

Palavras-chave: Imagem de Pensamento; Teoria Crítica; Escola de Frankfurt.

Em seu sentido estrito, Denkbild, ou imagem de pensamento, designa um gênero de escrita bastante restrito. Trata-se de uma prática composicional adotada por representantes da chamada Escola de Frankfurt e por alguns de seus interlocutores: além de Max Horkheimer, Walter Benjamin e T.W. Adorno, Ernst Bloch, Siegfried Kracauer e Bertold Brecht. ${ }^{2}$ Seu caráter circunscrito não reside somente na especificidade de seus autores, filósofos/críticos artistas ou artistas teoricamente engajados, mas também em seu curto período de existência, do final dos anos 1920 até possivelmente meados dos anos 1950. Para alguns (por exemplo, SCHLAFFER 1986: 190-192), com o

\footnotetext{
${ }^{1}$ Universidade Estadual de Campinas, Instituto de Estudos da Linguagem, Departamento de Teoria Literária, Rua Sérgio Buarque de Holanda, 571, 13083-859, Campinas, SP, Brasil. E-mail: fabioadurao@gmail.com

${ }^{2}$ Por exemplo, e respectivamente, Dämmerung [Crepúsculo] (2012); Rua de mão única. Infância berlinense (2013a); Minima Moralia Spüren [Vestígios]; Straßen in Berlin und anderswo [Ruas em Berlim e outros lugares] (2009); Geschichten von Herrn Keuner [Histórias do sr. Keuner] (2008). Também seria possível pensar aqui em obras compostas por herdeiros da Escola de Frankfurt, como Chronik der Gefühle [Crônica dos Sentimentos] (2004), de Alexander Kluge.
} 
Durão, F. A. - Imagem de pensamento como forma

desaparecimento das condições concretas de ruptura radical, a imagem de pensamento teria se tornado inviável no pós-Segunda Guerra - que dizer então nos dias de hoje, quando parece ser mais fácil imaginar o fim do mundo do que o do capitalismo? (cf. JAMESON 2003). O objetivo deste texto é argumentar na direção oposta e defender que, justamente devido ao estreitamento do horizonte do possível (cf. Hullot-Kentor 2008), a imagem de pensamento apresenta-se como um veículo promissor de crítica social, que mereceria ser retomado por escritores críticos. Porém, para que se possa vislumbrar plenamente seu potencial, e para que seja possível adaptar a imagem de pensamento às condições do presente, tanto em relação ao momento em que vivemos, quanto à realidade brasileira, é necessário abordá-la como forma, analisando seu modo de funcionamento e caracterizando seus méritos e fraquezas. ${ }^{3} \mathrm{O}$ primeiro passo é examinar os sentidos e a história da palavra.

Eberhard Wilhelm ScHULZ (1968: 218-252) oferece uma discussão abrangente de Denkbild. Seu campo semântico engloba seis significados principais:

1. Pensamentos, entendidos como uma imagem, que são produzidos ou formados pelo ato de pensar;

2. A imagem de uma coisa (Sache) feita pela mente (Geist) humana, no sentido de uma representação (Vorstellung) ou conceito;

3. O conteúdo (Inhalt) da mente, como pensamento, como opinião (Meinung), em relação a uma coisa;

4. Algo que forma todo um horizonte, um modo de pensar ou de encarar a vida;

5. "Ideia" no sentido platônico, ou seja, uma representação (Vorstellung) de uma coisa não relacionada à realidade;

6. Uma estátua ou tableau (Standbild) (monumentum) (cf. ScHULz 1968: 225226).

Essas acepções do uso comum do vocábulo já deixam entrever uma característica definidora, o primeiro traço formal da imagem de pensamento como tipo de escrita: a combinação de dois termos opostos, que podem ser articulados a partir de uma série de pares contrastantes, tais como conceito e mímesis, espontaneidade e mediação, experiência e conhecimento, relato e reflexão, caso e tese etc. Em suma, trata-se de um gênero no qual filosofia e literatura encontram-se inextricavelmente ligadas. São vários os modos como estes dois vetores entrelaçam-se; no Denkbild, imagem e pensamento

\footnotetext{
${ }^{3}$ Nem que com isso se esteja fazendo uma paleonomia, conferindo um sentido novo para um termo antigo, como argumenta RICHTER (2007: 1-8). Neste caso, o gênero "imagem de pensamento" surgiria mais de um conjunto de características derivadas de objetos até mesmo díspares, do que de uma origem atestada de antemão.
} 
Durão, F. A. - Imagem de pensamento como forma

agem um sobre o outro, seja como reforço mútuo, seja como tensão, o que faz com que a ênfase possa recair sobre um ou outro dos polos, como veremos adiante.

Antes disso, porém, duas palavras sobre a origem do termo. Embora ele tenha sido registrado já no século XVII, até o começo do XX não passava de uma curiosidade etimológica; hoje faz parte da linguagem corrente. Denkbeeld surgiu no holandês na segunda metade do século XVII como produto do nacionalismo linguístico humanista, que se esforçava para livrar o idioma de influências estrangeiras, nesse caso, idee. Ao ser transposto para o alemão, o vocábulo adquiriu o significado de emblema, uma imagem que traz consigo um sentido espiritual, que portanto aponta para além de si. Segundo ADORNO, “aqui está em jogo uma concepção de Platão, oposta ao neokantianismo, segundo a qual a Ideia não é uma mera representação mental Vorstellung), mas algo existente em si, algo que se deixa contemplar, ainda que apenas intelectualmente." (1974: 680). Não é à toa que o mesmo Benjamin que escreveu Imagens de pensamento (2013) tenha teorizado sobre a emblemática barroca em Origem do drama trágico alemão (2011). No Denkbild, imagens dão corpo a uma linguagem com uma sintaxe própria, e as letras surgem como coisas, em seu aspecto de desenho. Usando outra terminologia, é como se o significado entrasse em uma cadeia e o significante adquirisse espírito. Da mesma maneira que o leitor de emblemas procura decifrar o sentido oculto das representações pictóricas que tem em frente, o detalhe de um rosto, a posição de um objeto, o pensador crítico encara o mundo cotidiano, com tudo o que ele tem de fortuito e superficial, como um hieróglifo a ser desvendado. A diferença, contudo, está na relação com a realidade, pois para o compilador de Denkbilder o que está em jogo é a sua transformação. De novo Adorno, comentando as imagens de pensamento Benjamin:

Os fragmentos de Rua de mão única, no entanto, não são imagens como os mitos platônicos da caverna ou carruagem. Ao invés, são quebra-cabeças (Vexierbilder), invocações semelhantes a parábolas (gleichnishafte) daquilo que não pode ser dito em palavras. Querem menos parar o pensamento conceitual do que chocar por meio do que têm de enigmático, e assim fazer o pensamento mover-se, porque este, em sua forma tradicional, aparece como rígido, convencional e antiquado. Aquilo que não pode ser provado de modo usual, e todavia se impõe (bezwingt), deve impulsionar (anspornen) a espontaneidade e energia do pensamento, e, sem ser tomado literalmente, gerar faíscas, por meio de um tipo de curto-circuito intelectual, que subitamente lancem luz sobre, ou até incendeiem, o que é familiar (ADORNO 1974: 680-681, minha tradução). ${ }^{4}$

\footnotetext{
4 "Bilder jedoch sind die Stücke der Einbahnstraße nicht wie die platonischen Mythen von der Höhle oder vom Wagen. Es sind eher gekritzelte Vexierbilder als gleichnishafte Beschwörungen des in Worten Unsagbaren. Sie wollen nicht sowohl dem begrifflichen Denken Einhalt gebieten als durch ihre
} 
Durão, F. A. - Imagem de pensamento como forma

Com efeito, seria possível erigir a distância em relação à mudança radical como um parâmetro para a escrita da imagem de pensamento. Por exemplo, a presença da revolução é algo que diferencia marcadamente os fragmentos de Benjamin sobre Moscou (2013b: 19-50) dos de Minima Moralia, de AdORno (1992). E se o propósito deste texto é defender a vitalidade da imagem de pensamento como forma, ou seja, a possibilidade de ser utilizada no presente, então o afastamento da transformação real deve ser levado em conta.

Seja como for, existe um contexto amplo comum às diversas coleções de Denkbilder, já antecipado pela citação de Adorno acima. A mistura de conceito e mímesis, filosofia e literatura, só adquire veemência diante da crise generalizada de ambas, uma crise cujo primeiro sinal talvez resida em sua invisibilidade, no desgaste do discurso que deveria caracterizá-la, uma crise da fala sobre a crise. De qualquer modo, seria impossível abordar analiticamente tal nexo de cegueira, aquilo que Adorno chamou de Verblendungszusammenhang: alguns conceitos e questões não são produtivos quando encarados de frente (cf. DURÃo 2012a: 21). Que bastem, portanto, duas portas de entrada: a primeira, o que há de problemático na ideia de sistema filosófico, e na representação da totalidade que o acompanharia. Não há uma posição a partir da qual seria possível abordar alguma espécie de unidade do pensamento e da existência (em Hegel o Espírito Absoluto funcionava como lastro do foco narrativo do todo), e é disso que a filosofia analítica, uma solucionadora de problemas (BABICH 2012), extrai ao menos parte de sua força. Adorno, Benjamin, Bloch, Horkheimer e Kracauer compartilham, em sua escrita de Denkbilder, do projeto de fazer surgir, a partir da visão do pequeno, algo que o transcende e cuja validade quer-se ampla. Como colocou Adorno, "a análise social é capaz de extrair da experiência individual incomparavelmente mais do que admitia Hegel, ao passo que, inversamente, as grandes categorias históricas, depois de tudo aquilo que entrementes delas foi feito, não estão mais a salvo da suspeita de logro" (ADORNO 1992: 10). ${ }^{5}$ Outra porta de entrada é a da abstração, resultado inevitável da consolidação da sociedade de troca. O modo de impedir que Auschwitz seja visto como uma exceção, um sublime negativo que resiste a

Rätselgestalt schockieren und damit Denken in Bewegung bringen, weil es in seiner traditionellen begrifflichen Gestalt erstarrt, konventionell und veraltet dünkt. Was nicht im üblichen Stil sich beweisen läßt und doch bezwingt, soll Spontaneität und Energie des Gedankens anspornen und, ohne buchstäblich genommen zu werden, durch eine Art von intellektuellem Kurzschluß Funken Entzünden, die jäh das Vertraute umbeleuchten, wenn nicht gar in Brand stecken."

${ }^{5}$ Tradução ligeiramente modificada. 
qualquer verbalização, é mostrar o que o campo de concentração tem em comum com o discurso político baseado em estatísticas: o algarismo afasta daquilo que conta. Do ponto de vista da literatura, a presença do conceitual é benéfica diante do colapso no narrar, já celebremente teorizado por BENJAMIN (1994), diante da expropriação da experiência realizada pela proliferação da máquina. É interessante notar aqui a penetração do autômato já no próprio processo de composição textual. Como é possível sustentar uma história perante a codificação industrial-mercantil de enredos? Quando o comercial televisivo converte-se no modelo universal de organização narrativa - a mais perfeita concisão na utilização de recursos, e a lapidar combinação de som e imagem qualquer relato que reclame autenticidade levantará a suspeita de estar querendo vender algo. Devido ao seu componente reflexivo, a imagem de pensamento mostra-se imune às conotações que a indústria cultural desde o começo do século XX vem associando à literatura: ela resiste à sentimentalização e ao sacarino, à generalização humanista, e a leituras simbólicas. Aqui, o elemento racional, analítico surge como antídoto.

Isso não significa, porém, que a imagem de pensamento esteja imune à crise à qual responde. Seu caráter curto compartilha da fugacidade que marca o presente; o instante da iluminação não deixa de ter afinidades com a perda da profundidade histórica que se diz caracterizar o pós-modernismo (JAMESON 1991: 1-54). Talvez tudo dependa da acertada articulação entre o impulso subjetivo, o investimento no processo composicional e o apagamento do sujeito por meio do qual a coisa parece falar. Caso contrário, a relação com a vida corre o risco de recair em biografismo, a com o mundo, de perder-se no fait divers, a espontaneidade do pensamento, o momento do achado, de degradar-se em jornalismo.

A dupla fonte que alimenta a imagem de pensamento cria uma tensão no próprio gênero, pois ele poderá tender mais para a narração ou mais para a reflexão. Vestígios, de Bloch, tende para o primeiro caso, embora não se furte a fazer comentários. Um exemplo:

\section{O Negro (Der Schwarze)}

Alguém já se viu mais, justamente ao errar. Tarde da noite chegou esse senhor ao hotel, com amigos; todos os quartos estavam ocupados. À exceção de um, porém lá já dormia um negro; estamos na América. O senhor tomou o quarto mesmo assim, era só por uma noite, tinha que pegar o trem bem cedo. Ordenou ao atendente que batesse tanto na porta quanto na cama, e que atentasse para a certa, não a do negro. Durante a noite ingeriu-se toda sorte de bebidas fortes, de tal modo que os amigos, antes de levar o gentleman para o quarto do negro, pintaram-lhe o rosto de preto, sem que o notasse. 
Durão, F. A. - Imagem de pensamento como forma

Quando então o atendente despertou o estranho, este disparou para a estação, para o trem, para o banheiro, para lavar-se: eis que se vê no espelho e urra: "Diacho, aquele imbecil acabou acordando o negro." - A história é contada de maneiras diferentes, mas sempre com o mesmo resultado. O homem ainda estava bêbado de sono? Sem dúvida, e ao mesmo tempo nunca esteve tão desperto como naquele instante. Tão indefinidamente próximo a si, e, no entanto, sua brancura usual caiu-lhe do corpo como se tirasse um terno, embora confortável, no qual se está preso. Mesmo os brancos parecem na maior parte das vezes apenas imagens distorcidas de si, pois nada se encaixa; a vida é um mau alfaiate. $\mathrm{O}$ negro naturalmente perderia seu terno ainda mais rápido, se pestanejasse forte o suficiente ao menos uma vez (BLOCH 1985:35-36, minha tradução). ${ }^{6}$

O fragmento divide-se em duas partes, marcadas pelo travessão. Na primeira, conta-se uma história, na segunda, faz-se o comentário. Isso não quer dizer que não haja alguma interpenetração, pois a frase de abertura é uma tese, e o terno insere uma nova imagem na reflexão. A ideia central - a de que não somos o que pensamos ser, que determinações identitárias são veículos de opressão - soaria insossa se expressa em abstrato, ineficaz, se simplesmente exemplificada. Já estão presentes aqui dois importantes traços formais da imagem de pensamento para nossa discussão. Em primeiro lugar, o Denkbild não se fecha em si, mas contém, pelo contrário, uma abertura constitutiva, que se manifesta como sugestão para se continuar pensando. Em "O Negro" fica a instigação para refletir sobre como seria possível esvaziar as determinações identitárias sem precisar do equívoco - ou se, pelo contrário, este não seria o veículo por excelência para dissolver o eu enrijecido. Em outras palavras, o nó lógico do equívoco seria somente um meio de trazer à tona a falsidade da determinação identitária, ou representaria pelo contrário uma estratégia ou método? Incidentalmente, também valeria considerar o papel da intoxicação, tanto da bebida quanto do sono (curiosamente aproximados), como possibilitadores do engano-verdade, o que pode levar à crítica de uma concepção estreita da consciência.

\footnotetext{
6 "Der Schwarze. Einer blickte sich schon mehr an, grade indem er irrte. Spätabends kam ein Herr ins Hotel, mit Freuden, alle Betten waren besetzt. Außer einem, doch im Zimmer schlief bereits ein Neger, wir sind in Amerika. Der Herr nahm das Zimmer trotzdem, es war nur für eine Nacht, in aller Frühe mußte er auf den Zug. Schärfte daher dem Hausknecht ein, sowohl an de Türwecken als am Bett, und zwar am richtigen, nich an dem des Schwarzen. Auf die Nacht nahm man allerhand Scharfes, mit so viel Erfolg, daß die Freunde den Gentleman, bevor sie ihn ins Negerzimmer schafften, mit Ruß anstrichen und er es nicht einmal merkte. Wie nun der Hausknecht den Fremden geweckt hatte, er rast an den Bahnhof, in den Zug, in die Kabine, sich zu waschen: so sieht er sich im Spiegel und brüllt: "Jetzt hat der Dummkopf doch den Nigger geweckt." - Die Geschichte wird auch noch anders erzählt, läuft aber immer aufs Gleiche hinaus. War der Mann nicht verschlafen? gewiß, und er war zugleich nie wacher als in diesem Augenblick. So unbestimmt nah an sich selbst und die gewohnte Weiße fiel vom Leib wie ein Kleid, in das man ihn sonst, wenn auch ganz angenehm, gesteckt hatte. Auch die Weißen sehen meist nur dem Zerrbild von sich ähnlich; da sitzt nichts, das Leben ist ein schlechter Schneider. Dem Neger freilich fiel es ein Kleid noch mehr herunter, blinzelte er einmal scharf hin."
} 
Durão, F. A. - Imagem de pensamento como forma

O outro componente digno de nota é a forte presença da intersubjetividade, identificável em ao menos três níveis. "A história é contada de maneiras diferentes": ela não foi inventada por Bloch, não é sua propriedade, mas circula coletiva e anonimamente, sem ligação com traços identitários daquele que a conta. A escrita cuidadosa de Bloch não apaga o impulso oral do relato. O segundo nível do estar-junto não é o da circulação da história, mas o da própria narrativa, na bebedeira do senhor com os amigos. Note-se que este, um agente de dominação, não é visto como mau, nem incapaz de ter amigos ou se divertir. No mundo da história, a alegria do convívio é preservada. Por fim, há a interação motivada pelo próprio contato com o texto e pelo quanto este se deixa refletir e extrapolar: como seria o processo de libertação identitária do negro, "se pestanejasse forte o suficiente ao menos uma vez"? Como essa dinâmica de descentramento poderia ocorrer em questões de sexualidade? Ou em relações pós-coloniais? Existe algo de estimulante em ter ideias e a vontade de discuti-las é imanente à experiência de leitura.

O Denkbild também pode tomar conceitos ou palavras como objetos, como neste, de Minima Moralia:

Ninguém se lembre deles

A vida pregressa do emigrante, como se sabe, está anulada. Antigamente eram os mandados de captura, hoje é a experiência espiritual que é declarada intransferível e simplesmente exótica. $\mathrm{O}$ que não está reificado e não pode ser contado nem medido, deixa de existir. Mas, não bastasse isso, a reificação estende-se ao seu próprio contrário, à vida que não pode ser imediatamente atualizada; ao que só subsiste como pensamento e lembrança. Para isso inventaram uma rubrica própria, que se chama background, que aparece nos formulários após sexo, idade e profissão. A vida profanada é ainda por cima arrastada sobre o carro triunfal dos estatísticos unidos, e o próprio passado não está mais a salvo do presente, que o condena mais uma vez ao esquecimento no instante em que o recorda (ADORNO 1992: 39). ${ }^{7}$

Embora não haja menção a uma situação concreta, é possível reconstituí-la. Podemos imaginar o fragmento surgindo a partir das incontáveis vezes nas quais Adorno deve ter preenchido formulários que pediam o seu background. O termo promove uma redução extrema do vivido, daquilo que em última instância constitui o sujeito, em alguma

\footnotetext{
7 “Nicht gedacht soll ihrer werden. - Das Vorleben des Emigranten wird bekanntlich annulliert. Früher war es der Steckbrief, heute ist es die geistige Erfahrung, die für nicht transferierbar und schlechterdings artfremd erklärt wird. Was nicht verdinglicht ist, sich zählen und messen läßt, fällt aus. Nicht genug damit aber erstreckt sich die Verdinglichung selbst auf ihren eigenen Gegensatz, das nicht unmittelbar zu aktualisierende Leben; was immer bloß als Gedanke und Erinnerung fortlebt. Dafür haben sie eine eigene Rubrik erfunden. Sie heißt "Hintergrund" und erscheint als Appendix der Fragebogen, nach Geschlecht, Alter und Beruf. Das geschändete Leben wird auch noch auf dem Triumphauto der vereinigten Statistiker mitgeschleppt, und selbst das Vergagene ist nicht mehr sicher vor der Gegenwart, die es nochmals dem Vergessen weiht, indem sie es erinnert."
} 
Durão, F. A. - Imagem de pensamento como forma

categoria pré-existente. Designar o background representa assim uma traição ao passado, uma lembrança pior do que o esquecimento, uma vez que este pode gerar toda sorte de efeitos interessantes (como muito bem mostrou HELLER-RoAZEN (2010), em relação à língua). Essa eliminação do qualitativo é causa e consequência da dominação social que a estatística proporciona. Note-se que a imagem de pensamento une semanticamente o background aos mandatos de captura, realizando assim um gesto de aproximação da perseguição totalitária aos mecanismos de controle das democracias liberais. Tal gesto é precioso e contrasta radicalmente com as abordagens que lidam com as tragédias passadas, por exemplo, o Holocausto, como desvinculadas do presente (cf. DURÃo 2015:107-108). Em comparação com a imagem de pensamento de Bloch, a de Adorno estabelece uma curiosa relação de opostos: se a primeira, narrativamente mais concreta, leva a uma extrapolação filosófica poderosa a respeito da falsidade de determinações identitárias, nas quais se baseia uma forte dominação social, a de Adorno, mais geral, apresenta um forte potencial de estranhamento. Os formulários tornaram-se tão comuns que geraram um automatismo, mesmo que mal-humorado, em torno de si. Trazer à mente o que há de violência neles produz um choque criticamente produtivo.

Neste ponto vale a pena atentar para outra importante característica formal da imagem de pensamento: ela faz surgir uma não-identidade do/no existente. Em Minima Moralia, por exemplo, há um recorrente movimento de contraposição do capitalismo liberal do século XIX ao monopolista, dos dias de Adorno. Isso foi motivo para que o seu autor tenha sido chamado de nostálgico, saudosista, como se cem anos atrás o mundo fosse simplesmente melhor. Isso não é verdadeiro. O passado funciona aqui como termo de comparação, item rigorosamente relacional, que ajuda a fazer sobressair a negatividade do presente, pois é este que está em jogo. Se o foco recaísse no século XIX, surgiria outro elemento (o século XVIII?) que permitiria a busca da nãoidentidade. Para dizer de outra maneira: passado e presente não estão à disposição do historiador como uma objetividade inerte, mas interferem um no outro. O presente abre um passado específico ${ }^{8}$ e o passado estabelece um contraponto com o presente, permitindo que este apareça como não necessário. O correlato espacial dessa mistura

\footnotetext{
${ }^{8}$ É somente por isso que Horkheimer e Adorno, na Dialética do Esclarecimento, são capazes de identificar em Ulisses o primeiro burguês. Esse achado só se torna vislumbrável diante da exponencial mercantilização da sociedade e da total expansão do princípio de troca. Um presente diferente reconfiguraria o passado.
} 
Durão, F. A. - Imagem de pensamento como forma

são as viagens. Não é à toa que elas ocupam um lugar tão proeminente nas Imagens de Pensamento de Benjamin, e que o exílio seja constitutivo de Minima Moralia. Para Kracauer, espaço e tempo misturam-se na cidade. Ao perambular aparentemente sem rumo, observa:

E, no entanto, a rigor, não me faltava um destino. Cria tê-lo, mas para meu infortúnio esquecia-o. Sentia-me como uma pessoa que busca por uma palavra em sua memória, que está na ponta da língua, mas que não consegue encontrá-la. Cheio de desejo (Begierde) de finalmente atingir o lugar no qual o esquecido me viesse à mente, não podia passar pela menor viela sem adentrá-la e dobrar a esquina atrás dela. O melhor seria se pudesse examinar todos os quintais, investigar recinto a recinto. Quando desse modo espreitava por todos os lados, do sol às sombras e de novo à luz do dia, tinha a clara sensação (Empfindung) de que, na busca do destino desejado, não me movia somente no espaço, como também com frequência transpunha seus limites e penetrava no tempo. Uma trilha de contrabandista secreta levava ao território das horas e das décadas, cujo sistema de ruas era labirinticamente traçado como o da própria cidade (KRACAUER 2009:10, minha tradução). ${ }^{9}$

Note-se como aqui a perda de si não é conseguida senão com esforço, que a desorientação é norteada pela certeza de que o local a que se deseja chegar existe. Se o Denkbild é um gênero produtor de não-identidades, em Adorno isso é muitas vezes alcançado com o choque entre o presente em rápida transformação com um passado ainda vivo na memória; no caso de Benjamin, o confronto ocorre entre lugares díspares; para Kracauer o vagar traz os dois em conjunção.

A relação entre fragmentos leva à questão de sua coerência. A imagem de pensamento dificilmente existe sozinha. Nisso, diferencia-se, de um lado, da poética imagista, dos haicais etc., e, de outro, da crônica. Tomados individualmente, os Denkbilder trazem em si o vazio de uma totalidade para a qual apontam, mas que não veem. ${ }^{10} \mathrm{~A}$ imagem de pensamento não se basta a si mesma; ela não é capaz de explicar o que descreve, e essa lacuna, na qual se insere o leitor, faz parte de sua estrutura. É do seu acúmulo, bem como da sedimentação de temas recorrentes ou aparentados, de

\footnotetext{
9 "Und doch war ich, streng genommen, nicht ziellos. Ich glaubte ein Ziel zu haben, aber ich hatte das Ziel zu meinem Unglück vergessen. Es war mir zumute wie einem Menschen, der in seinem Gedächnis nach einem Wort sucht, das ihm auf den Lippen brennt, und er kann es nicht finden. Von der Begierde erfüllt, endlich an den Ort zu gelangen, an dem mir das Vergessene wieder einfiele, konnte ich nicht die kleinste Nebengasse streifen, ohne sie zu betreten und hinter ihr um die Ecke zu biegen. Am liebsten hätte ich sämtliche Höfe ergründet und Zimmer für Zimmer durchforscht. Wenn ich so nach allen Seiten spähte, aus der Sonne in die Schatten und wieder zurück nach dem Tag, hatte ich die deutliche Empfindung, daß ich mich, auf der Suche nach dem gewüschten Ziel, nicht nur im Raum bewgte, sondern oft genug seine Grenzen überschritt und in die Zeit eindrang. Ein geheimer Schmugglerpfad führte ins Gebiet der Stunden und Jahrzehnte, dessen Straßensysteme ebenso labyrinthisch angelegt war wie das der Stadt selber."

${ }^{10}$ É interessante comparar o tipo de lacuna projetado pela imagem de pensamento com aquele que Roberto SCHWARZ (2012) identificou na poesia de Chico Alvim.
} 
Durão, F. A. - Imagem de pensamento como forma

suplementações e associações, de tensões e contradições, muitas vezes não intencionais, que se dá a formação de nexos de sentido, ${ }^{11}$ que necessariamente devem deixar elementos de fora. Para usar termos da linguística textual, nas imagens de pensamento há coerência sem haver coesão. Adorno aproxima esse tipo de lógica à figura do jogador; segundo ele, "o pensamento renuncia a qualquer ilusão (Schein) de segurança da organização do espírito, à dedução, indução e conclusão, entregando-se à sorte e ao risco de apostar na experiência e encontrar algo de essencial.” (1974: 682). Há uma aposta dupla em jogo, a de que, em sua entrega ao fugaz e transitório, a escrita seja capaz de penetrar em algo de relevante, e a de que o leitor consiga preencher, com a sua própria experiência - de vida e de leitura - os vazios da exposição. Isso se aplica não apenas a imagens de pensamento isoladas, mas à sua combinação. Dada sua fluidez, os elementos de ligação dependem em grande medida das articulações que o leitor estabelecer. Os pontos de contato, portanto, variarão com o tempo e com as preocupações de quem os estiver interpretando. Isso não quer dizer que o componente subjetivo imponha-se simplesmente, pois aqui a liberdade de proposição de temas está em tensão com a necessária coerência do todo. Se os Denkbilder pendem demais para este, passam a assemelhar-se a exemplos, mesmo que de uma tese não enunciada; se o negam, dispersam-se em histórias que aparecerão como aleatórias, na melhor das hipóteses, ou como resultantes do capricho do sujeito, na pior.

Isso ocorre porque, apesar de haver unidades temáticas, algo próximo a capítulos, não há nos livros de Denkbilder um desenvolvimento propriamente dito na sucessão de tópicos. Cada imagem de pensamento lança o foco sobre algo, coloca à frente, pro-põe um assunto. A liberdade de transitar entre um e outro é das características mais marcantes do gênero, a tal ponto que o Denkbild pode, com imagens, refletir explicitamente sobre si mesmo:

\section{Sinal secreto}

Há um dito de Schuler ${ }^{12}$ que passou de boca em boca. Dizia ele que todo conhecimento deve conter um grãozinho de contrassenso, como os padrões das tapeçarias antigas ou os frisos ornamentais, nos quais se descobria sempre algum pequeno desvio em relação

\footnotetext{
${ }^{11}$ Isso talvez possa ser tomado como critério. Obras fragmentadas que não cristalizem, que não formem nós a partir de segmentos díspares e aparentemente não relacionados, teriam nisso uma fraqueza. Salvo engano, isso é o que acontece com um texto ambicioso como Eles eram muitos cavalos, de Luiz RUFFATO (2013). Já John Cage, por outro lado, em seus mesósticos e no reading through, para não mencionar o próprio 4'33', parece questionar a própria dinâmica da sedimentação, ao tornar caótico, indiferente ou insignificante o material a ser lido (cf. DURÃo 2005).

12 “Alfred Schuler (1865-1923): escritor alemão que contribuiu, com Ludwig Klages, para a redescoberta de Baschofen, por quem Benjamin também se interessou”. [Nota de João Barrento].
} 
Durão, F. A. - Imagem de pensamento como forma

ao seu desenvolvimento regular. Por outras palavras: o que é decisivo não é a passagem de conhecimento a conhecimento, mas o salto adentro de cada conhecimento. É ele o sinal insignificante da autenticidade, que o distingue de toda mercadoria de série fabricada a partir de um molde (BENJAMIN 2013b: 119). ${ }^{13}$

Aqui também há a transmissão oral, uma frase que, se possui uma autoria, foi apropriada por muitos; e aqui também surge uma imagem que se liga ao conceito, que se opõe à mercadoria. Ora, esse é o modus operandi do livro no qual se encontra esse fragmento, assim como, forçando um pouco, o pulo do "contrassenso" aos "padrões das tapeçarias antigas". A metáfora ou o símile são imagens que ao mesmo tempo sabem de si como tais.

Outro exemplo é o do Denkbild 44, de Minima Moralia, segundo o qual:

[...] Desse ponto de vista, pensar dialeticamente quer dizer que o argumento deve adquirir o caráter drástico da tese, e a tese conter em si a plenitude de seu funcionamento. Todos os conceitos que servem de ponte, todas as conexões e as operações lógicas auxiliares que não fazem parte da coisa mesma, todas as deduções secundárias e não saturadas da experiência do objeto devem ser descartados. Em um texto filosófico, todas as proposições deveriam situar-se a igual distância do centro. [...] (ADORNO 1992: 61). ${ }^{14}$

Sem dúvida, o ideal de constelação expresso aqui por Adorno não é exclusivo da imagem de pensamento (cf. DURÃo 2012b: 41-69); porém ele útil para pensar a relação, nas imagens de pensamento, entre dialética e totalidade, pois aqui aquela funciona sem uma versão extensiva e abrangente desta. O todo, aqui, é antes intensivo, passível de estar presente no mais diminuto. Além disso, o jogo das oposições pode ocorrer em um contexto no qual há restos, se não tanto no interior de cada Denkbild, então certamente em seu acúmulo. No limite, a imagem de pensamento seria capaz de lançar uma luz mesmo sobre as obras filosóficas mais rigorosas, como a Dialética Negativa (ADORNO 2009), que assim perderiam a ambição de exaustão de tudo conter em si, algo que Adorno já criticava em Hegel. De qualquer modo, dessa autoconsciência composicional resulta um teor enigmático. Ao misturar o "o quê", o conteúdo, à forma de exposição,

13 "Geheimzeichen. Man überlierfert mündlich ein Wort von Schuler. In jeder Erkenntnis müsse, so sagte er, ein Quentschen Wiedersinn enthalten sein, wie die antiken Teppichmuster oder Ornamentfriese von ihrem regelmäßigen Verlauf immer irgendwo eine geringfügige Abweichung erkennen ließen. Mit andern Worten: Nicht der Fortgang von Erkenntnis zu Erkenntnis ist entscheidend, sonder der Sprung in jeder einzelnen Erkenntnis selbst. Er ist die unscheinbare Echtheitsmarke, die sie von aller Serienware unterscheidet, die nach Schablone angefertigt ist."

14 “[...] Dialektisch denken heißt, unter diesem Aspekt, daß das Argument die Drastik der These gewinnen soll und die These die Fülle ihres Grundes in sich enthalten. Alle Brückenbegriffe, alle Verbindungen und logischen Hilfsoperationen, die nicht in der Sache selber sind, alle sekundären und nicht mit der Erfahrung des Gegenstands gesättigten Folgerungen müßten entfallen. In einem philsophischen Text sollten alle Sätze gleich nahe zum Mittelpunkt stehen.” 
Durão, F. A. - Imagem de pensamento como forma

ao "como", a imagem de pensamento mostra que sabe o que está em jogo no processo de escrita e interpretação. Em outras palavras, a posição textualmente designada ao leitor não é simplesmente um efeito da narração/reflexão, mas está planejadamente instaurada; desse modo, ele mesmo deve atentar para o lugar que ocupa diante do que é apresentado.

A esta altura, podemos recapitular as três principais características formais da imagem de pensamento desenvolvidas até aqui. Como uma mistura híbrida de representação e reflexão, resultado de uma crise do pensamento no século XX, ela tem como motor o inconformismo e como horizonte regulador a transformação total, a revolução. Do ponto de vista de seus vários praticantes, o Denkbild diferencia-se internamente por pender mais para um dos extremos, o da mímesis ou o da lógica, sem nunca abandonar o outro. Dado que não existem isoladamente, as imagens de pensamento estabelecem um tipo de coerência baseado na sedimentação de ideias recorrentes em posições argumentativas diferentes, incluindo seu contrário; como há muito que não se encaixa, surge uma interessante dialética do nexo e do resto. Por fim, a autoconsciência do Denkbild problematiza o espaço ocupado pelo leitor. Tudo isso pode funcionar como base para aquilo que seria o aspecto mais determinante dessa forma de escrita: sua essência prática. Porque a imagem de pensamento apresenta-se como um veículo privilegiado para mediar o livro e o mundo, a biblioteca e o bar (cf. DURÃO 2015: 64-65); ela somente funciona como objeto, como aquilo que é, na medida em que consegue transmitir uma experiência. A mímesis possui aqui duas dimensões, pois ela comunica não apenas a presença do todo no pequeno, mas também a liberdade subjetiva que ousa arriscar-se no contraintuitivo.

No começo deste texto, chamei a atenção para o argumento de que a imagem de pensamento não seria mais possível diante do caráter distópico do presente. A ausência de uma força revolucionária iminente, como nas décadas de 1920 ou 1930, ou mesmo de um sujeito coletivo transformador, como talvez em 1968, neutralizaria o impulso mais decisivo do Denkbild. Porém, é possível que o contrário seja o caso. Se o aprofundamento da dominação pode dificultar mobilizações abrangentes, isso tem como pressuposto sua crescente ubiquidade, prestando-se assim a ser objeto da imagem de pensamento. Quanto mais a dominação se faz presente em todos os lugares, tanto mais pode prosperar um tipo de escrita que tem como alvo seu desvelamento sob a forma do conceito mimetizado e da mímesis conceitualizada. Mesmo nos casos mais extremos, 
Durão, F. A. - Imagem de pensamento como forma

como o de Minima Moralia - ou melhor, mais claramente neles, à visibilidade do negativo corresponde uma alegria catártica ${ }^{15}$ uma descarga afetiva oriunda do reconhecimento retroativo e do tomar-forma na escrita. Em outras palavras, a difusão cada vez mais intensa da lógica da mercadoria nos poros mais íntimos da vida psíquica e social pede um tipo de crítica capaz de trazer em si a ênfase do vivido, e de mostrar como a realidade aparentemente total poderia ser outra; a rapidez cada vez maior dos meios de difusão da linguagem, dos fluxos de mensagens (DURÃo 2008), faz surgir a necessidade de uma escrita que possa interromper a corrente significante isolando um objeto ou um acontecimento; finalmente, a solidão do pensamento (e do pensador) encontra um antídoto ao menos parcial em um tipo de escrita que, mesmo enigmática, almeja a comunicação do inconformismo. Longe de ser um gênero desgastado, condenado pelos rumos do mundo, o Denkbild possui uma notável vitalidade latente, esperando para ser redescoberta.

\section{Referências bibliográficas}

Adorno, T.W. Minima Moralia. Traduçãode Luiz Eduardo Bicca. São Paulo: Ática, 1992 [1951].

AdORNO, T. W. Benjamins Einbahnstraße. In: Noten zur Literatur. Frankfurt a.M.: Suhrkamp, 1998 [1974].p. 680-685.

Adorno, T. W. Dialética Negativa. Traduçãode Marco Antonio Casanova. Rio de Janeiro: Zahar, 2009 [1966].

BABICH, Babette. La fin de la pensée? Philosophie analytique contre philosophie continental. Paris: L'Harmattan, 2012.

BENJAMIN, Walter. O Narrador. Considerações sobre a obra de Nikolai Leskov. In:

Magia e técnica, arte e política: ensaios sobre literatura e história da cultura. Traduçãode Sérgio Paulo Rouanet. São Paulo: Brasiliense, 1994 [1936]. p. 197-221.

Benjamin, Walter. Origem do drama trágico alemão. Tradução de João Barrento. Belo Horizonte: Autêntica, 2011 [1928].

Benjamin, Walter. Rua de mão única: infância berlinense. Traduçãode João Barrento. Belo Horizonte: Autêntica, 2013a [1928; 1950].

Benjamin, Walter. Imagens de Pensamento -Sobre o haxixe e outras drogas.Tradução de João Barrento. Belo Horizonte, 2013b [1972].

BERNARD, Andreas; RAULFF, Ulrich. "Minima Moralia" neu gelesen. Frankfurt a.M.: Surhkamp, 2003.

BLOCH, Ernst. Spuren. Frankfurt a.M.: Suhrkamp, 1985 [1930].

\footnotetext{
${ }^{15}$ Para a teoria crítica, a dominação é existencialmente imediata. Isso significa que é necessário mais trabalho conceitual para apagá-la do que para percebê-la. A crítica frequente que se faz a Minima Moralia, que o livro repousa mais sobre uma estrutura de crença do que de argumentação, não estaria errada se "crença" denominasse um saber pré-conceitual oriundo da experiência cotidiana da desigualdade e exploração.
} 
Durão, F. A. - Imagem de pensamento como forma

BRECHT, Bertold. Histórias do sr. Keuner. Tradução de Paulo César de Souza. São Paulo: Editora 34, 2006 [1930-1957].

DURÃo, Fabio A. Duas formas de se ouvir o silêncio: revisitando 4'33". Kriterion, Belo Horizonte, v. XLVI, n.112, p. 429-441, 2005.

DURÃO, Fabio A. Da superprodução semiótica: caracterização e implicações estéticas. In: DURÃO, Fabio A. et.al. A indústria cultural hoje. São Paulo: Boitempo Editorial, 2008. p. 39-48.

DURÃO, Fabio A. Entrevistas com Robert Hullot-Kentor. São Paulo: Nankin, 2012a.

DURÃO, Fabio A. Modernismo e coerência. Quatro capítulos de uma estética negativa. São Paulo: Nankin, 2012b.

DURÃo, Fabio A. Fragmentos reunidos. São Paulo: Nankin, 2015.

DURÃo, Fabio A. Perspectivas da crítica literária hoje. Sibila, ano 17, 23/03/2016. Disponível em: 〈http://sibila.com.br/critica/perspectivas-da-critica-literaria-hoje/12433〉. Acesso em: 12 jul. 2017.

Düttmann, Alexander García. So ist es. Ein philosophischer Kommentar zu Adornos' Minima Moralia. Frankfurt a.M.: Suhrkamp, 2004.

Heller-RoAZEn, Daniel. Ecolalias. Sobre o esquecimento das línguas. Tradução de Fabio Akcelrud Durão. Campinas: Editora da Unicamp, 2010.

HORKHEIMER, Max. Dämmerung.Gesammelte Schriften, Bd. 2. Frankfurt a.M.: Fischer, 1987 [1934].

Hullot-Kentor, Robert. A New Type of Human Being, and Who We Really Are.The Brooklyn Rail, 10/11/2008. Disponível em: <http://brooklynrail.org/2008/11/art/a-newtype-of-human-being-and-who-we-really-are online>. Acesso em: 12 jul. 2017.

HUYSSEN, Andreas. Miniature Metropolis. Literature in an Age of Photography and Film. Cambridge: Harvard University Press, 2015.

JAMESON, Fredric. Postmodernism; or, the cultural logic of late capialism. Durham: Duke University Press, 1991.

JAMESON, Fredric. Future City. New Left Review, v. 21, p. 65-79, maio-junho, 2003.

KIRST, Karoline. Walter Benjamin's Denkbild: Emblematic Historiography of the Recent Past. Monatshefte, v. 86, n. 4, p. 514-524,Winter, 1994.

KLUGE, Alexander. Chronik der Gefühle. Frankfurt a.M.: Suhrkamp, 2004.

KraCAUER, Siegfried. Straßen in Berlin und anderswo. Frankfurt a. M.: Suhrkamp, 2009 [1964].

MORSON, Gary Saul. The Long and the Short of It. Stanford: Stanford University Press, 2012.

RICHTER, Gerhard. Thought-Images. Frankfurt School Writers' Reflections from Damaged Life. Stanford: Stanford University Press, 2007.

RufFATO, Luiz. Eles eram muitos cavalos. São Paulo: Companhia das Letras, 2013.

SCHLAFFER, Heinz. Denkbilder: Eine kleine Prosaform zwischen Dichtung und Gesellschafttheorie. In: ELM, Theo; HIEBEL, Hans Helmut (Ed.) Die Parabel. Frankfurt a.M.: Suhrkamp, 1986. p. 174-194.

SCHULZ, Eberhard Wilhelm. Wort Und Zeit. Aufsätze Und Vortrage Zur Literaturgeschichte. Kiel: Karl Wachholtz Verlag, 1968.

SCHWARZ, Roberto. Um minimalismo enorme. In : Martinha versus Lucrécia. São Paulo: Companhia das Letras, 2012. p. 111-142. 